\title{
IMPLICAÇÕES DA USABILIDADE APARENTE COMO CRITÉRIO PARA A ESCOLHA DE REVESTIMENTOS CERÂMICOS PARA MORADIA
}

\section{IMPLICATIONS OF APPARENT USABILITY AS A TOUCHSTONE FOR CHOICE OF CERAMIC COATING FOR HOUSING}

\author{
Izabel Nascimento ${ }^{1}$, Mestranda \\ Raimundo Lopes Diniz², D. Sc. \\ Lívia Campos ${ }^{3}$, D. Sc. \\ Cláudia Mont'Alvão ${ }^{4}$, D. Sc.
}

(1) Universidade Federal do Maranhão

e-mail: izabel.nas13@gmail.com

(2) Universidade Federal do Maranhão

e-mail: rl.diniz@ufma.br

(3) Universidade Federal do Maranhão

e-mail: liviaflavia@gmail.com

(4) Departamento de Artes e Design/PUC-Rio

e-mail: cmontalvao@puc-rio.br

Usabilidade aparente, processo de escolha, piso cerâmico

Este artigo apresenta uma pesquisa descritiva de consumidores de pisos cerâmicos em uma loja em São Luís-MA. Observou-se a relevância que a usabilidade aparente tem no processo de escolha quando consumidores realizam a compra a partir de opiniões pessoais quanto à estética e a métodos empíricos de observação das características técnicas. A partir dessa observação, este estudo apresenta a fundamentação teórica dos conceitos e aplicações da ergonomia e usabilidade, e reflexões sobre a capacidade de comunicação que os produtos têm de informar o consumidor.

\section{Apparent usability, touchstone choice, ceramic floor}

This article presents a descriptive survey of ceramic floors' consumers in a store in São Luís-MA. It was observed the relevance that the apparent usability has in the process of choice when consumers make the purchase from personal opinions regarding aesthetics and empirical methods of observation of technical characteristics. From this observation, this study presents the theoretical basis of the concepts and applications of ergonomics and usability, and reflections on the communication capacity that the products have, to inform the consumer. 
$16^{\circ}$ Ergodesign - Congresso Internacional de Ergonomia e Usabilidade de Interfaces Humano Tecnológica: Produto, Informações Ambientes Construídos e Transporte

$16^{\circ}$ USIHC - Congresso Internacional de Ergonomia e Usabilidade de Interfaces Humano Computador

CINAHPA | 2017 - Congresso Internacional de Ambientes Hipermídia para Aprendizagem.

\section{Introdução}

O consumo não é apenas um meio de se evidenciarem gostos, caprichos e compras impulsivas, mas sim uma apropriação pessoal de um produto (CANCLINI, 2010) na busca por satisfazer suas necessidades e desejos a partir do seu uso (LÖBACH, 2001). Este consumo, quando voltado às necessidades pessoais de um indivíduo, adquirindo um produto em pequena quantidade, através de um varejista, tendo seu uso direcionado ao ambiente residencial ou social, define a mercadoria em questão enquanto um produto de consumo (FALCÃO \& SOARES, 2013). Partindo do entendimento do processo de compra dentro deste universo individualizado, este trabalho considera os pisos cerâmicos aplicados à moradia como produtos de consumo, e busca entender o contexto de escolha deles relacionando os critérios pessoais do consumidor com as especificações técnicas determinadas nas normas desenvolvidas para este tipo de produto.

A escolha feita pelo consumidor que desconhece as normas técnicas aplicadas aos pisos cerâmicos levou a reflexão sobre a usabilidade deste produto. $\mathrm{O}$ consumidor geralmente não é especializado ou treinado para conhecer os dados técnicos que definem a aplicabilidade ideal para um piso, ficando, assim, exposto ao uso diferente do especificado pelo fabricante, principalmente quando escolhem, sem acompanhamento de um profissional, o piso para sua própria casa. Ele recorre a técnicas empíricas intencionando, inconscientemente, escolher um produto que tenha os atributos obrigatórios em um processo de fabricação e nomenclatura dos pisos, e os esperados por ele. Apesar de o termo usabilidade ser mais conhecido em estudos sobre a interação humano-computador (FALCÃO \& SOARES, 2013), neste artigo, a referência a ele se dá considerando a usabilidade aparente, que faz referência a compra dele a partir da aparência que o torna atraente e impulsiona o consumo (CAMPOS, 2014).

Contudo, não cabe considerar apenas a aparência como fator a ser considerado para o uso. Existem normas que determinam tanto as características que devem estar presentes nos pisos, como o controle de sua aplicabilidade ideal a partir de testes. Esses índices são definidos em normas que qualificam um piso em coeficientes, classificando-os quanto ao acabamento, método de fabricação, capacidade de absorção de água, resistência a abrasão, resistência ao manchamento, resistência ao ataque de agentes químicos e aspecto superficial e visual (NBR 13817:1997; NBR 13818:1997). Definem também características físicas e químicas que os tornam mais indicados para áreas como piscinas, saunas, indústrias, contato com alimentos, entre outros (NBR 13818:1997). Esses critérios orientam profissionais e vendedores na indicação deste tipo de produto, bem como deveriam servir de orientação ao consumidor no processo de escolha do piso cerâmico.

O presente artigo organiza-se em quatro tópicos que conduzem o leitor dentro dos conceitos de usabilidade e ergonomia e como elas se relacionam aos produtos pisos cerâmicos. A primeira identifica o que caracteriza um produto como sendo de consumo, como ele deve ser pensado com base em sua usabilidade, quais as contribuições da ergonomia a este tipo de produto, e a influência da usabilidade aparente no momento de sua compra. Depois, o leitor é levado a entender como o piso cerâmico foi relacionado a um produto de consumo e quais características os enquadram neste grupo, seguindo-se então a uma explanação sobre as determinações normativas que obrigam algumas caracterizações deste material. Partindo deste entendimento, é feito um paralelo dos critérios e conceitos da ergonomia e como eles são aplicados aos pisos cerâmicos. Ao final, são apresentados três exemplos reais, a partir de uma pesquisa descritiva, com a observação sistemática preliminar em uma loja de pisos, com a aplicação dos conhecimentos descritos anteriormente e reflexões sobre o processo de caracterização deste material para os consumidores e da forma de informá-los sobre suas características.

\section{Usabilidade e ergonomia em produtos de consumo}

Um produto, para ser consumido, necessita possuir 


\section{$16^{\circ}$ \\ ERGODESIGN USIHC CINAHPA}

$16^{\circ}$ Ergodesign - Congresso Internacional de Ergonomia e Usabilidade de Interfaces Humano Tecnológica: Produto, Informações Ambientes Construídos e Transporte

$16^{\circ}$ USIHC - Congresso Internacional de Ergonomia e Usabilidade de Interfaces Humano Computador

CINAHPA | 2017 - Congresso Internacional de Ambientes Hipermídia para Aprendizagem. atributos que tornem seu uso de fácil entendimento para quem compra, bem como deve ter suas funcionalidades compatíveis com as necessidades desse consumidor. Para isso, segundo Iida (2005), ele deve possuir qualidades técnicas, quando se mostra eficiente para a função a que se destina; ergonômicas, sendo fácil de usar e entender sua função; e estéticas, quando consegue despertar no consumidor o desejo para comprá-lo a partir de critérios como cor, textura, material, etc.

A Norma ISO 9241-11:2002 explica que um produto para ter usabilidade deve atingir objetivos específicos, de maneira rápida e com pouco esforço para um consumidor específico, em um contexto específico de uso. Ela não pode ser analisada de maneira ampla sem considerar especificidades do contexto de uso. Se um produto não se enquadra nestes critérios para o consumidor, provavelmente ele deixará de fazer parte do mercado, seja por imposições normativas de controle, ou pela não execução da compra. Outro fator importante a se observar no uso de um produto é a relação que seu estudo deve ter com a prevenção de acidentes.

A ergonomia contribui nesta prevenção, pois se interessa pelo estudo das interações do ser humano com os produtos. Desde a década de 70 que profissionais especialistas em ergonomia se integram na equipe de projeto sendo fundamentais nas especificações das características de um produto (IIDA, 2005). Eles contribuem na configuração dos produtos, mas também na maneira como as informações serão absorvidas pelo usuário, o que ajuda na aplicação adequada a que o produto foi destinado. Um produto de consumo que não é desenvolvido dentro de requisitos usabilidade e ergonomia poderá ser o responsável por causar acidentes (SOARES \& CORREIA, 2002). Por isso, seu projeto deve prever, além das características do produto pensadas na fábrica, aquelas que o consumidor considerará que o produto possui.

\subsection{Usabilidade aparente do produto}

Independentemente das atribuições de um produto, ele só será adquirido se o consumidor antes do uso, ou seja, ainda na loja, perceber estes atributos. Existem casos também em que o consumidor realiza uma compra inadequada porque o produto parecia ter as funções que ele necessitava. Isto se dá, conforme Campos (2014), ao fato do consumidor/usuário ter sido atraído pela usabilidade aparente do produto, somados a motivos como preço, tamanho, estética, etc.

Essa usabilidade aparente deve ser considerada com atenção pelos projetistas, pois ela pode mudar, e o usuário passar a ter outros anseios, ou ter mudanças em sua vida que o levam a outras necessidades (McDonagh et al., 2005). Outro risco desta usabilidade está quando, após o uso, o produto mostra-se ineficaz e ineficiente frente aos anseios de quem o comprou, o que pode comprometer a relação do usuário com este produto, bem como, em alguns casos, provocar sérios acidentes. Isso mostra que a usabilidade deve ser avaliada em fases distintas do produto, ou seja, antes de ser lançado no mercado, durante a escolha dele e na fase de uso (CAMPOS, 2014). Esta reflexão é feita por Krucken (2009), sobre a perspectiva da qualidade, em que o produto possui três níveis: a qualidade esperada, a percebida e a experimentada. Ao final, a usabilidade esperada de uma mercadoria deve ser a mesma experimentada após seu uso.

\section{Revestimentos cerâmicos a partir das Normas Técnicas}

O processo de desenvolvimento de revestimentos cerâmicos ancora-se no respeito às normas que definem sua terminologia e classificação, bem como os métodos de ensaios para este tipo de material. Elas são, respectivamente, a NBR 13816:1997, a NBR 13817:1997 e a NBR 13818:1997. Existem também normas que orientam sobre o correto assentamento deste produto, tais como: NBR 9817:1987 e NBR 13753:1996. Contudo, poucas informações presentes nelas chegam ao conhecimento do consumidor.

$\mathrm{O}$ acesso a elas permite o correto entendimento de informações que elas obrigam as lojas a dispor em etiquetas informativas fixadas junto aos produtos
Realização:

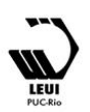




\section{$16^{\circ}$ \\ ERGODESIGN USIHC CINAHPA}

que ela normatiza. Segundo a NBR 13818:1997, "nos catálogos, folhetos técnicos e informativos das empresas devem constar obrigatoriamente as seguintes informações: grupo de classificação; classe de abrasão de 0 a 5; classe de resistência química, $A, B$ ou $C$; classe de resistência ao manchamento de 0 a 5 e coeficiente de atrito para pisos". Contudo, não há uma determinação de como essas informações devem estar dispostas nas lojas. E também não prevê a forma como o consumidor receberá suas informações.

A Figura 1 mostra uma etiqueta de piso cerâmico, como um exemplo, na maior rede de lojas de São Luís-MA, para este tipo de produto. Ela é uma das orientações que o consumidor tem para definir qual piso é ideal às suas necessidades. As informações presentes nela informam que o piso possui PEI 5, $6 \%$ a $10 \%$ de absorção de água, acabamento granilhado e esmaltado, uso residencial e comercial pesado, vantagens de ser fácil de limpar, alta resistência e possui classificação A.

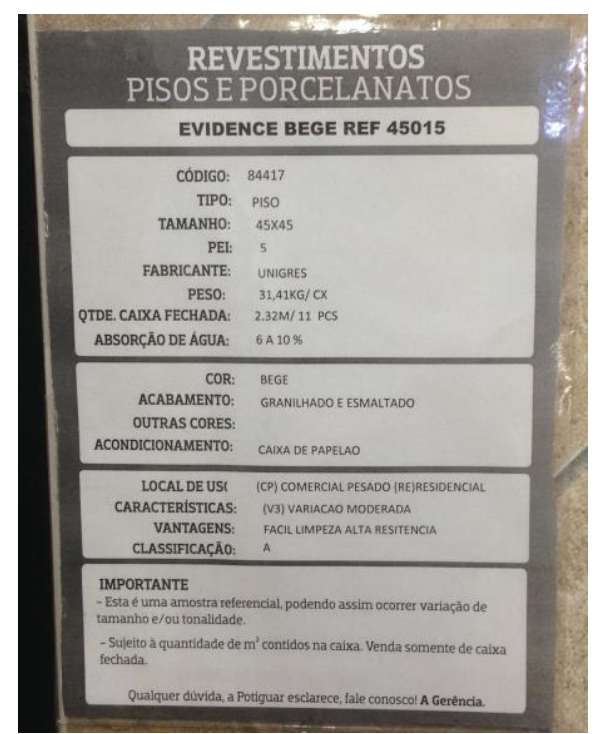

Figura 1 - Etiqueta de uma loja de revestimentos cerâmicos. Fonte: Elaborada pela autora.

Estas informações descrevem as características deste produto e informam sobre sua melhor aplicabilidade. Entretanto, o consumidor precisa saber o que implica esta taxa de absorção de água, o que é PEI 5, e o que significa ele ser de classificação A. Provavelmente, um consumidor não familiarizado com estas indicações sentir-se-á $16^{\circ}$ Ergodesign - Congresso Internacional de Ergonomia e Usabilidade de Interfaces Humano Tecnológica: Produto, Informações Ambientes Construídos e Transporte

$16^{\circ}$ USIHC - Congresso Internacional de Ergonomia e Usabilidade de Interfaces Humano Computador

CINAHPA | 2017 - Congresso Internacional de Ambientes Hipermídia para Aprendizagem.

inseguro quanto à sua compra e correta aplicação.

\section{Métodos e técnicas}

Esta pesquisa buscou compreender a interação do consumidor com o produto, no processo de escolha dele. Entendendo que a ergonomia se utiliza de metodologias das ciências sociais ao realizar uma pesquisa, optou-se nesta fase preliminar pela realização de uma pesquisa descritiva, em que o pesquisador observa a situação real, sem interferir nela, a fim de fazer o levantamento de opiniões e comportamentos do público observado (GIL, 2008). Para isso, foi realizada, de forma exploratória, uma observação sistemática de consumidores, desacompanhados de profissionais, no momento da escolha de revestimentos cerâmicos, para a sua moradia. Este tipo de pesquisa não busca encontrar uma verdade absoluta, mas fazer indagações sobre um fenômeno observado.

Segundo Gil (2008), este tipo de observação possibilita ao pesquisador identificar aspectos relevantes às pessoas estudadas, a fim de atingir os objetivos da pesquisa, tendo para isso, um planejamento prévio sobre como será realizada a observação. Nesta pesquisa-piloto, foi determinado um roteiro a ser seguido pelo pesquisador que consistia na abordagem aos clientes no momento de acesso a área de venda de revestimentos cerâmicos, seguida da apresentação da pesquisa e explicação de detalhes quanto à confidencialidade do estudo e liberdade de recusa do participante a qualquer momento. Foi explicado também que seriam tiradas fotos das opções de revestimentos que eles mais gostassem, bem como das opções escolhidas. Outra explicação dada, neste momento inicial, foi sobre a inexistência de comportamentos certos ou errados, pois o objetivo seria justamente identificar ações desconhecidas dos fabricantes e projetistas, mas que são peculiares aos consumidores. Para não interferência sobre a escolha dos revestimentos foi explicado que o pesquisador apenas acompanharia cada um, tomando nota em anotações no papel sobre comportamentos e comentários.

Devido à pesquisa necessitar de abordagem e
Realização:
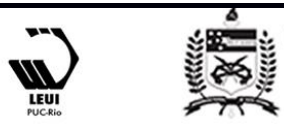


\section{$16^{\circ}$ \\ ERGODESIGN USIHC CINAHPA}

observação de consumidores no interior de uma loja de revestimentos cerâmicos, foi escolhida a maior loja para este tipo de produto, implantada na cidade de São Luís-MA. O agendamento do dia foi realizado a partir de solicitação por ofício, mas por coincidir com período natalino, foi disponibilizado apenas 1 (um) dia com fluxo médio de clientes.

\subsection{Os revestimentos cerâmicos enquanto produto e consumo}

Para a pesquisa foi necessário caracterizar os revestimentos cerâmicos e definir os aspectos a serem considerados para identificá-lo como um produto de consumo. Um produto de consumo deve cumprir alguns requisitos como: ser usado para o que o usuário intencionou no momento da compra; e partir de uma aquisição pessoal, submetendo-se a critérios subjetivos, em que o comprador não é treinado sobre as características daquele produto (IIDA, 2005).

Nesta pesquisa, na qual o produto é o piso cerâmico, comprado para moradia, por pessoas que o escolhem sem ajuda de profissionais, ele foi considerado como um bem de consumo. A Tabela 1 mostra uma relação entre as características de um bem de consumo definidas por Iida (2005), e as características dos pisos cerâmicos considerados para esta pesquisa.

\begin{tabular}{|c|c|c|}
\hline FATORES & $\begin{array}{c}\text { BENS DE } \\
\text { CONSUMO }\end{array}$ & $\begin{array}{c}\text { PISOS } \\
\text { CERÂMICOS }\end{array}$ \\
\hline Objetivo & $\begin{array}{l}\text { Selecionado pelo } \\
\text { usuário }\end{array}$ & $\begin{array}{l}\text { O consumidor } \\
\text { define o local da } \\
\text { moradia onde irá } \\
\text { assentar o piso }\end{array}$ \\
\hline Comprador & $\begin{array}{l}\text { Individual, } \\
\text { podendo } \\
\text { predominar } \\
\text { critérios subjetivos }\end{array}$ & $\begin{array}{l}\text { Vai a loja } \\
\text { desacompanhado } \\
\text { de um profissional }\end{array}$ \\
\hline Usuário & $\begin{array}{l}\text { Genérico, sem } \\
\text { treinamento } \\
\text { específico }\end{array}$ & $\begin{array}{l}\text { Genérico, sem } \\
\text { conhecimento sobre } \\
\text { os critérios técnicos }\end{array}$ \\
\hline $\begin{array}{l}\text { Acompanhamento } \\
\text { do uso }\end{array}$ & Não existe & $\begin{array}{l}\text { A loja não sabe } \\
\text { como será aplicado }\end{array}$ \\
\hline Manutenção & $\begin{array}{l}\text { Corretiva, para } \\
\text { corrigir falhas }\end{array}$ & $\begin{array}{l}\text { Corretiva, } \\
\text { provocadas pelo } \\
\text { assentamento } \\
\text { inadequado }\end{array}$ \\
\hline Custo da falha & $\begin{array}{l}\text { Disperso, difícil } \\
\text { quantificar }\end{array}$ & Disperso \\
\hline Renovação & $\begin{array}{l}\text { Frequente, sujeito a } \\
\text { moda e mudanças } \\
\text { formais }\end{array}$ & $\begin{array}{l}\text { Não é frequente, } \\
\text { mas está sujeito ao } \\
\text { gosto pessoal }\end{array}$ \\
\hline
\end{tabular}

Tabela 1 - Adaptada pela autora para caracterização dos $16^{\circ}$ Ergodesign - Congresso Internacional de Ergonomia e Usabilidade de Interfaces Humano Tecnológica: Produto, Informações Ambientes Construídos e Transporte

$16^{\circ}$ USIHC - Congresso Internacional de Ergonomia e Usabilidade de Interfaces Humano Computador

CINAHPA | 2017 - Congresso Internacional de Ambientes Hipermídia para Aprendizagem.

\section{Resultados}

Durante a pesquisa de observação, que aconteceu no período de 1 (um) dia, foram abordados casais e grupos de famílias. Não foi observada, durante a pesquisa, a ida de clientes sozinhos para a escolha de revestimentos cerâmicos. As famílias, principalmente aquelas que acompanhavam algum parente idoso, foram mais receptíveis à participação, pois os casais jovens geralmente diziam-se constrangidos com uma pessoa acompanhando-os por todo o setor de revestimentos. Algumas pesquisas nãos puderam ser bem realizadas, pois, por ter ocorrido em período natalino, em alguns momentos não era possível escutá-los devido o áudio da loja estar anunciando produtos e músicas de natal. Entretanto, foi possível uma pesquisa completa com cinco grupos, nos quais três serão apresentados neste trabalho, devido à maior relevância ao tema pesquisado.

Os casos descritos abaixo fazem referência ao processo de escolha de três grupos de consumidores compostos e caracterizados da seguinte maneira: consumidor 1, uma senhora idosa, acompanhada da filha e neta, escolhendo um piso para o banheiro do marido, cadeirante e idoso; consumidor 2, uma senhora idosa, acompanhada de dois filhos adultos, escolhiam um piso para a cozinha da casa dela; consumidor 3 , uma senhora idosa, acompanhada de dois filhos jovens e da nora, escolhendo um piso para a sala de estar e um revestimento para a parede do jardim, da casa da senhora.

No primeiro caso, consumidor 1 , a intenção das clientes era comprar um piso que não fosse escorregadio, por se tratar de um banheiro para um cadeirante idoso. Para isso, voltaram suas escolhas a três tipos de piso antiderrapante (Figuras 2, 3 e 4) a fim de suprir a necessidade principal pelo produto comprado.

Realização:

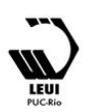




\section{$16^{\circ}$ \\ ERGODESIGN USIHC CINAHPA}

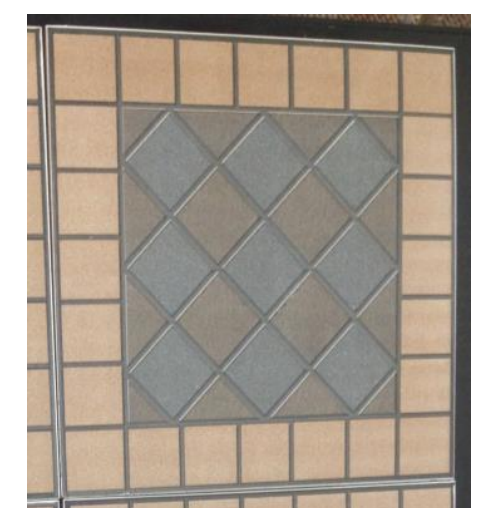

Figura 2 - risu alliuchapaind. 1 Unte. Liaborada pela autora.

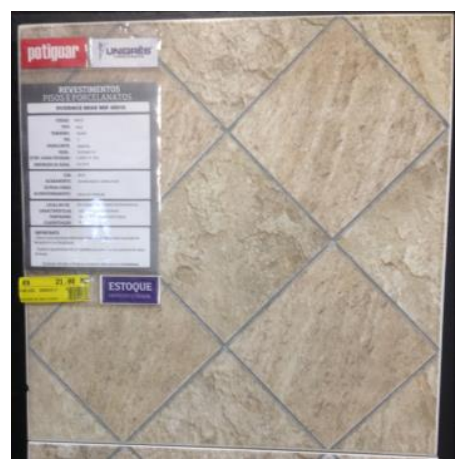

Figura 3 - Piso antiderrapante. Fonte: Elaborada pela autora.

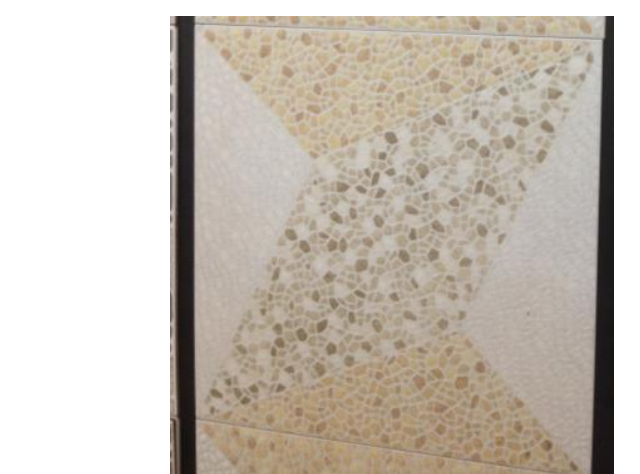

Figura 4 - Piso antiderrapante. Fonte: Elaborada pela autora.

No processo de escolha foi observado o constante toque da mão sobre o piso para entendimento de ele ser escorregadio ou não. Dentre as três opções, as clientes optaram pelo piso da Figura 3, sob o argumento pessoal de este ter cores mais "equilibradas" que as outras opções disponíveis na loja e de que este seria provavelmente menos propenso a manchas causadas pelo contato com $16^{\circ}$ Ergodesign - Congresso Internacional de Ergonomia e Usabilidade de Interfaces Humano Tecnológica: Produto, Informações Ambientes Construídos e Transporte

$16^{\circ}$ USIHC - Congresso Internacional de Ergonomia e Usabilidade de Interfaces Humano Computador

CINAHPA | 2017 - Congresso Internacional de Ambientes Hipermídia para Aprendizagem.

shampoo, sabonete ou condicionador, quando usado em um banheiro. As informações do fabricante, presentes na etiqueta da loja indicavam local de uso mais adequado como comercial pesado ou residencial, PEI 5, fácil limpeza e alta resistência (Figura 1). Informações que não foram consideradas no momento de escolha.

O segundo caso, consumidor 2, o grupo buscava por revestimentos cerâmicos de piso para assentar na cozinha da mãe, uma senhora idosa. Um dos critérios de escolha era também o piso não ser escorregadio. Para esta avaliação no momento da compra, eles tocavam as opções que lhes chamavam mais atenção. Outro comportamento de escolha foi a rotação do piso encostando todas as laterais com outro semelhante (figura 5), como verificação "da existência de um lado correto de assentamento", justificativa do filho mais novo.

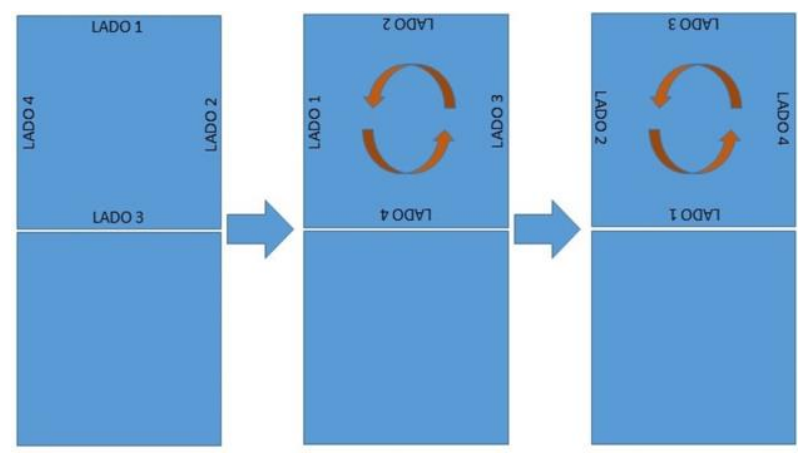

Figura 5 - Desenho esquemático do giro da cerâmica realizado pelo consumidor. Fonte: Elaborada pela autora

Ao final da avaliação de toque da mão e rotação dos pisos que foram considerados no momento da escolha, ficaram em dúvida sobre duas opções, ambos pisos esmaltados e lisos, que foram considerados pelos clientes como uma opção apropriada, não escorregadia. A senhora idosa fez a opção pelo piso na cor preta (Figura 6) e os filhos preferiram o piso na cor bege (Figura 7). 


\section{$16^{\circ}$ \\ ERGODESIGN USIHC CINAHPA}

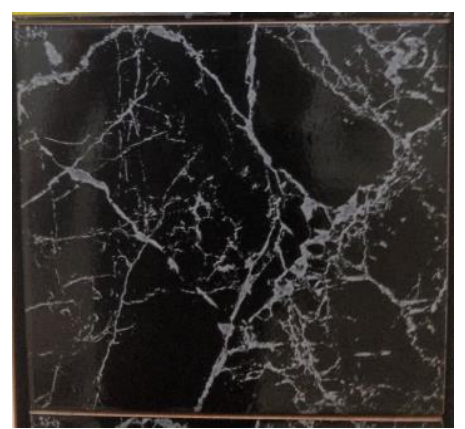

Figura 6- Opção de piso preto considerado pela cliente. Fonte: elaborada pela autora.

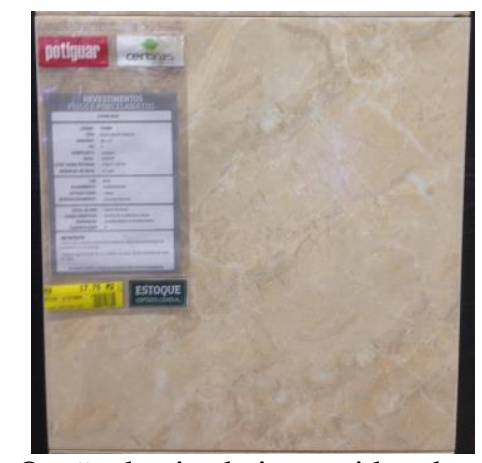

Figura 7 - Opção de piso beje considerado pela cliente. Fonte: elaborada pela autora.

Ao final compraram o piso ilustrado na Figura 7, sob o argumento de que, apesar de gostarem muito do piso na cor preta, este ficaria melhor para ser usado em ambientes como sala de estar ou quarto da casa; e que o piso bege combinaria melhor com a cozinha, que é toda branca. Este exemplo mostra também motivos exclusivamente de gosto pessoal e, apesar de presentes e tendo suas informações observadas pelas pessoas, nenhum dos dados técnicos constantes nas etiquetas foi determinante na escolha do produto.

Um terceiro grupo, consumidor 3 , composto por uma senhora idosa, dois filhos e uma nora, jovens com idade entre 25 e 35 anos, chamou atenção pela leitura constante das etiquetas. Eles estavam escolhendo um piso para a sala e um revestimento de parede para o jardim, ambos para a casa da mãe. Foi observada grande influência dos filhos na escolha que definiram aspectos como: um piso resistente ao risco e um revestimento com poucos detalhes. O primeiro aspecto, resistência a riscos, era "testado" pelo filho, passando a chave do carro sobre os pisos, na tentativa de identificar aqueles resistentes à abrasão, informação não constante nas $16^{\circ}$ Ergodesign - Congresso Internacional de Ergonomia e Usabilidade de Interfaces Humano Tecnológica: Produto, Informações Ambientes Construídos e Transporte

$16^{\circ}$ USIHC - Congresso Internacional de Ergonomia e Usabilidade de Interfaces Humano Computador

CINAHPA | 2017 - Congresso Internacional de Ambientes Hipermídia para Aprendizagem.

etiquetas. Este teste e a experiência pessoal levaram-nos a discordar da mãe sobre a compra de um porcelanato, pois comentavam que este tipo de piso tem facilidade de manchamento e riscos. Eles também tocavam com as mãos todos os pisos para entender qual estaria mais adequado à casa de uma avó, que além de idosa, recebe sempre os filhos e netos em casa, argumento exposto pela filha.

O segundo aspecto, a existência de poucos detalhes, era também discordante com a vontade da mãe. Com comentários, principalmente do filho, frente a opções estampadas na loja (Figura 8), como: "mamãe só gosta destas coisas assim... amarelo...", ou "esse é bom para fazer um detalhe... não dá para botar todo dele". Este grupo, apesar de olhar todas as opções da loja, optou por adiar a compra para outro momento, pois não conseguiram concordar com um produto ideal.

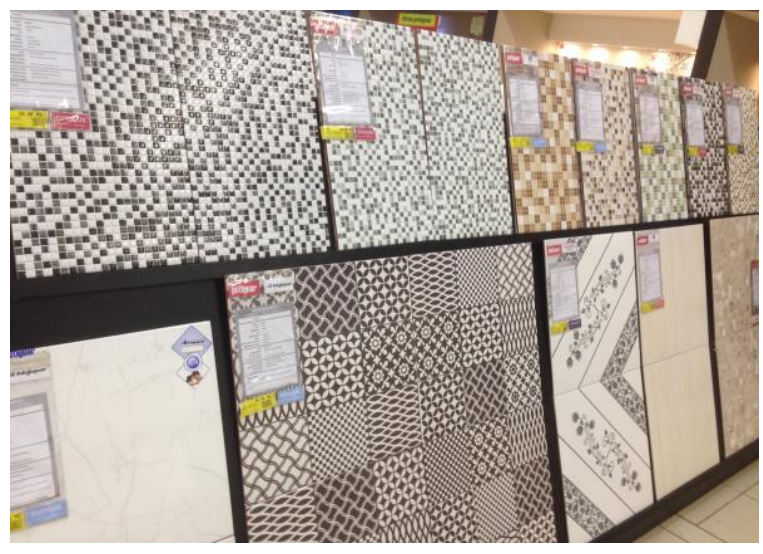

Figura 8 - Opções de revestimento de parede com superfície estampada considerado pela cliente. Fonte: elaborada pela autora.

Foi observada nos três casos a influência direta dos filhos sobre a escolha do revestimento mais adequado e também comunicando ao pesquisador as opiniões sobre os revestimentos da loja. Em todos os casos, a opinião dos idosos, proprietários moradores das casas que receberão o material, era ouvida, mas seguida da tentativa de convencimento da opinião dos filhos.

Todos os grupos utilizaram o toque das mãos para decidir sobre a usabilidade do produto, tanto avaliando a possibilidade de ser escorregadio quanto a facilidade de limpeza da superfície depois de assentada a placa cerâmica. Algumas técnicas
Realização:
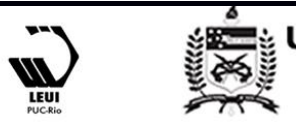


\section{$16^{\circ}$ \\ ERGODESIGN USIHC CINAHPA}

$16^{\circ}$ Ergodesign - Congresso Internacional de Ergonomia e Usabilidade de Interfaces Humano Tecnológica: Produto, Informações Ambientes Construídos e Transporte

$16^{\circ}$ USIHC - Congresso Internacional de Ergonomia e Usabilidade de Interfaces Humano Computador

CINAHPA | 2017 - Congresso Internacional de Ambientes Hipermídia para Aprendizagem. de escolha como o giro das peças para definição do lado melhor de assentamento, quanto o uso da chave do carro para avaliar a resistência à abrasão, foram particulares de alguns consumidores e observadas como empíricas a partir de experiências anteriores com o mesmo tipo de produto.

Em todos os casos as informações técnicas das etiquetas da loja e nas etiquetas de preço foram consideradas apenas na etapa inicial de escolha, sendo a opinião pessoal o fator determinante de escolha, tanto se referindo à estética da superfície do revestimento quanto à sua capacidade de suprir suas necessidades individuais. $\mathrm{O}$ formato das placas de revestimento cerâmico não influenciou nenhuma das escolhas observadas.

\section{Conclusão}

Esta pesquisa inicial levou a uma inquietação sobre como as etiquetas devem informar as características dos revestimentos cerâmicos e quais outras informações são necessárias para melhor informação dos consumidores. Isto direciona também uma reflexão sobre os motivos que os levam a ler as etiquetas, mas não a considerar suas informações no momento da escolha. Sendo mais recorrente a escolha por razões pessoais de gosto dentro de critérios estéticos. Instigou também uma reflexão sobre as sensações de que o toque do piso exprime no consumidor a ponto de ele preferir fazer o julgamento da possibilidade de escorregar sem considerar os coeficientes de atrito do mesmo.

Foi observado também que as informações inerentes dos pisos bem como aquelas impressas em etiquetas identificadoras não permitem que o usuário entenda, em sua totalidade, todo o universo de suas possibilidades de uso, considerando também a probabilidade de usos inadequados deste material. Cabe aos projetistas e fabricantes a preocupação em fornecer este universo de especificações de forma clara e inteligível, pois dados dispostos em normas e com a utilização de termos técnicos não alcançam o entendimento dos consumidores.

O processo de projetação, fabricação e lançamento no mercado, para os pisos cerâmicos, deve, assim como outros produtos, considerar a participação da ergonomia. Revestimentos pensados a partir dela estabelecem relações mais próximas às necessidades do consumidor. Conhecer a usabilidade que um revestimento irá aparentar possuir para o consumidor, e considerá-la ainda na fase de projeto e fabricação, evitará escolhas inadequadas às necessidades de quem o compra. Saber que o usuário busca identificá-la com o toque da mão, implica em desenvolver gradações de texturas condizentes com a facilidade de uso, segurança e facilidade de limpeza, fatores importantes aos seus usuários, bem como a composição estética, considerando a variedade de gostos.

Diante do mercado existente atualmente para este tipo de produto, sua compra não depende mais da posse de um projeto, onde todas as características estão especificadas, ficando a escolha, em muitos casos, sujeita a critérios como gosto pessoal, preço e tamanho das peças. Partindo-se deste entendimento, os pisos devem seguir o mesmo percurso dos outros produtos desenvolvidos e considerar as expectativas de quem poderá adquirilo. Ele deve ser projetado dentro dos padrões técnicos definidos nas normas, mas sem deixar de considerar o universo subjetivo ao qual ele poderá ser inserido. Certamente, o projeto deve considerar os padrões técnicos, mas deve também inserir características sensoriais compatíveis aos padrões normativos, a fim de permitir que o consumidor, que desconhece estes padrões, possa escolher adequadamente o piso da sua casa, tendo seus anseios e necessidades supridos em sua totalidade, sem exposição dele aos riscos da escolha inadequada deste produto. Isto faz a análise do contexto de uso e escolha dos revestimentos cerâmicos relevantes para propiciar a qualidade de vida aos seus usuários, assunto a ser investigado no prosseguimento desta pesquisa.

\section{BIBLIOGRAFIA}

ASSOCIAÇÃO BRASILEIRA DE NORMAS TÉCNICAS. NBR 13817: Placas cerâmicas para revestimento - Classificação. Rio de Janeiro, 1997.
Realização:
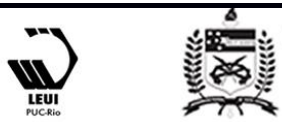


\section{$16^{\circ}$}

ERGODESIGN USIHC CINAHPA

\section{ASSOCIAÇÃO BRASILEIRA DE NORMAS}

TÉCNICAS. NBR 9241-11. Requisitos

Ergonômicos para Trabalho de Escritórios com Computadores - Parte 1 - Orientações sobre Usabilidade. Rio de Janeiro, 2002.

\section{ASSOCIAÇÃO BRASILEIRA DE NORMAS}

TÉCNICAS. NBR 13818: Placas cerâmicas para revestimento - Especificação e métodos de ensaios. Rio de Janeiro, 1997.

CAMPOS, Lívia F. A. Usabilidade, percepção estética e força de preensão manual: influência no design ergonômico de instrumentos manuais um estudo com tesouras de poda. 2014. 269 f. Tese (Doutorado em Design) - Universidade Estadual Paulista. Faculdade de Arquitetura, Artes e Comunicação, Bauru, 2014.

CANCLINI, Néstor Garcia. Consumidores e cidadãos: conflitos multiculturais da globalização. 8. ed. Rio de Janeiro: Editora UFRJ, 2010.

FALCÃO, C. S.; SOARES, M. M. Usabilidade de Produtos de Consumo: uma análise dos conceitos, métodos e aplicações. Estudos em Design. Revista (online). Rio de Janeiro: v. 21, n. 2, 2013, p. 01-26.

GIL, Antonio Carlos. Métodos e técnicas de pesquisa social. São Paulo: Atlas, 2008.

IIDA, Itiro. Ergonomia: projeto e produção. 2. ed. São Paulo: Edgard Blücher, 2005.

KRUCKEN, Lia. Design e território: valorização de identidades e produtos locais. São Paulo: Studio Nobel, 2009.

LÖBACH, Bernd. Design industrial: bases para a configuração dos produtos industriais. São Paulo: Editora Blucher, 2001.

MCDONAGH, Deana; HEKKERT, Paul; VAN ERP, Jeroen; GYI, Diane (edit.). Design and Emotion: The Experience of Everyday Things. London and New York: Taylor \& Francis, 2005.

SOARES, Marcelo M.; CORREIA, Walter F. M. Usabilidade e segurança nos produtos de consumo: um diferencial na qualidade do design.
Congresso Internacional de Pesquisa e Desenvolvimento em Design, v.5, 2002. nterfaces Humano Tecnológica: Produto, Informações Ambientes Construídos e Transporte

$16^{\circ}$ USIHC - Congresso Internacional de Ergonomia e Usabilidade de Interfaces Humano Computador

CINAHPA | 2017 - Congresso Internacional de Ambientes Hipermídia para Aprendizagem. 